\title{
Human fetal osteoblast response on poly(methyl methacrylate)/polystyrene demixed thin film blends: Surface chemistry vs topography effects
}

Raechelle A. D'Sa ${ }^{1}$, Jog Raj ${ }^{2}$, Peter J. Dickinson ${ }^{2}$, Fiona McCabe ${ }^{2}$ and Brian J. Meenan ${ }^{2}$

${ }^{1}$ Centre for Materials and Structures, University of Liverpool, Brownlow Hill, Liverpool, L69 $3 \mathrm{GH}, \mathrm{UK}$

${ }^{2}$ Nanotechnology and Integrated Bio-Engineering Centre (NIBEC), University of Ulster, Shore Road, Newtownabbey, BT37 OQB, UK

* Dr. Raechelle D’Sa

Centre for Materials and Structures,

University of Liverpool, Brownlow Hill,

Liverpool, L69 3GH, UK

Email: $\underline{\text { r.dsa@liverpool.ac.uk }}$ 
Table S1: XPS Derived C1s and 01s Atom \% and C1s Curve Fitted Data for polymer demixed films

\begin{tabular}{|c|c|c|c|}
\hline Sample & O 1s & C 1s & O/C \\
\hline PMMA & $23.7 \pm 0.5$ & $76.3 \pm 0.5$ & 0.31 \\
\hline PMMA $_{75} P_{25}$ & $25.4 \pm 0.7$ & $74.6 \pm 0.7$ & 0.35 \\
\hline $\mathrm{PMMA}_{50} \mathrm{PS}_{50}$ & $25.1 \pm 0.9$ & $74.9 \pm 0.9$ & 0.33 \\
\hline $\mathrm{PMMA}_{25} \mathrm{PS}_{75}$ & $22.3 \pm 1.4$ & $77.7 \pm 1.4$ & 0.28 \\
\hline $\mathrm{PS}$ & $0.5 \pm 0.0$ & $99.5 \pm 0.0$ & 0.005 \\
\hline $\mathrm{PMMA}_{\mathrm{DBD}}$ & $28.4 \pm 0.3$ & $41.5 \pm 6.8$ & 0.4 \\
\hline $\mathrm{PMMA}_{75} \mathrm{PS}_{25 \mathrm{DBD}}$ & $27.5 \pm 1.4$ & $72.5 \pm 1.4$ & 0.38 \\
\hline $\mathrm{PMMA}_{50} \mathrm{PS}_{50 \mathrm{DBD}}$ & $27.6 \pm 0.9$ & $72.4 \pm 0.9$ & 0.38 \\
\hline $\mathrm{PMMA}_{25} \mathrm{PS}_{75 \mathrm{DBD}}$ & $21.6 \pm 0.7$ & $78.4 \pm 0.7$ & 0.28 \\
\hline $\mathrm{PS}_{\mathrm{DBD}}$ & $8.3 \pm 0.7$ & $91.7 \pm 0.7$ & 0.09 \\
\hline
\end{tabular}

Table S2: High Resolution C1s Curve Fitted XPS Data for polymer demixed films

\begin{tabular}{|c|c|c|c|c|c|}
\hline \multirow{2}{*}{ Sample } & \multicolumn{5}{|c|}{ C 1s } \\
\cline { 2 - 6 } & C-C/C-H & $\beta$-shifted C & C-O & O=C-0 & $\pi-\pi^{*}$ \\
\hline PMMA & $41.5 \pm 4.0$ & $25.1 \pm 3.0$ & $19.1 \pm 0.6$ & $14.9 \pm 1.3$ & \\
\hline PMMA $_{75} P_{25}$ & $41.3 \pm 0.8$ & $15.8 \pm 1.6$ & $25.1 \pm 1.0$ & $17.7 \pm 0.4$ & \\
\hline PMMA $_{50} P_{50}$ & $37.6 \pm 1.1$ & $17.5 \pm 0.6$ & $26.5 \pm 1.2$ & $18.4 \pm 0.4$ & \\
\hline PMMA $_{25} P_{75}$ & $46.4 \pm 5.0$ & $16.4 \pm 2.8$ & $23.9 \pm 2.6$ & $12.0 \pm 0.8$ & $1.3 \pm 0.5$ \\
\hline $\mathrm{PS}$ & $92.6 \pm 0.9$ & 0 & 0 & 0 & $7.4 \pm 0.9$ \\
\hline $\mathrm{PMMA}_{\mathrm{DBD}}$ & $35.4 \pm 1.8$ & $25.9 \pm 4.0$ & $19.2 \pm 4.7$ & $19.5 \pm 0.1$ & \\
\hline $\mathrm{PMMA}_{75} \mathrm{PS}_{25 \mathrm{DBD}}$ & $40.8 \pm .9$ & $16.2 \pm 0.9$ & $24.6 \pm 1.3$ & $18.5 \pm 0.4$ & \\
\hline $\mathrm{PMMA}_{50} \mathrm{PS}_{50 \mathrm{DBD}}$ & $39.4 \pm 1.4$ & $16.0 \pm 1.3$ & $25.4 \pm 0.5$ & $19.0 \pm 0.2$ & \\
\hline $\mathrm{PMMA}_{25} \mathrm{PS}_{75 \mathrm{DBD}}$ & $41.6 \pm 2.3$ & $25.0 \pm 2.2$ & $19.8 \pm 0.7$ & $12.8 \pm 0.3$ & $0.8 \pm 0.4$ \\
\hline $\mathrm{PS}_{\mathrm{DBD}}$ & $63.0 \pm 4.3$ & $20.8 \pm 1.9$ & $9.6 \pm 2.1$ & $3.3 \pm 1.0$ & $3.3 \pm 0.6$ \\
\hline
\end{tabular}



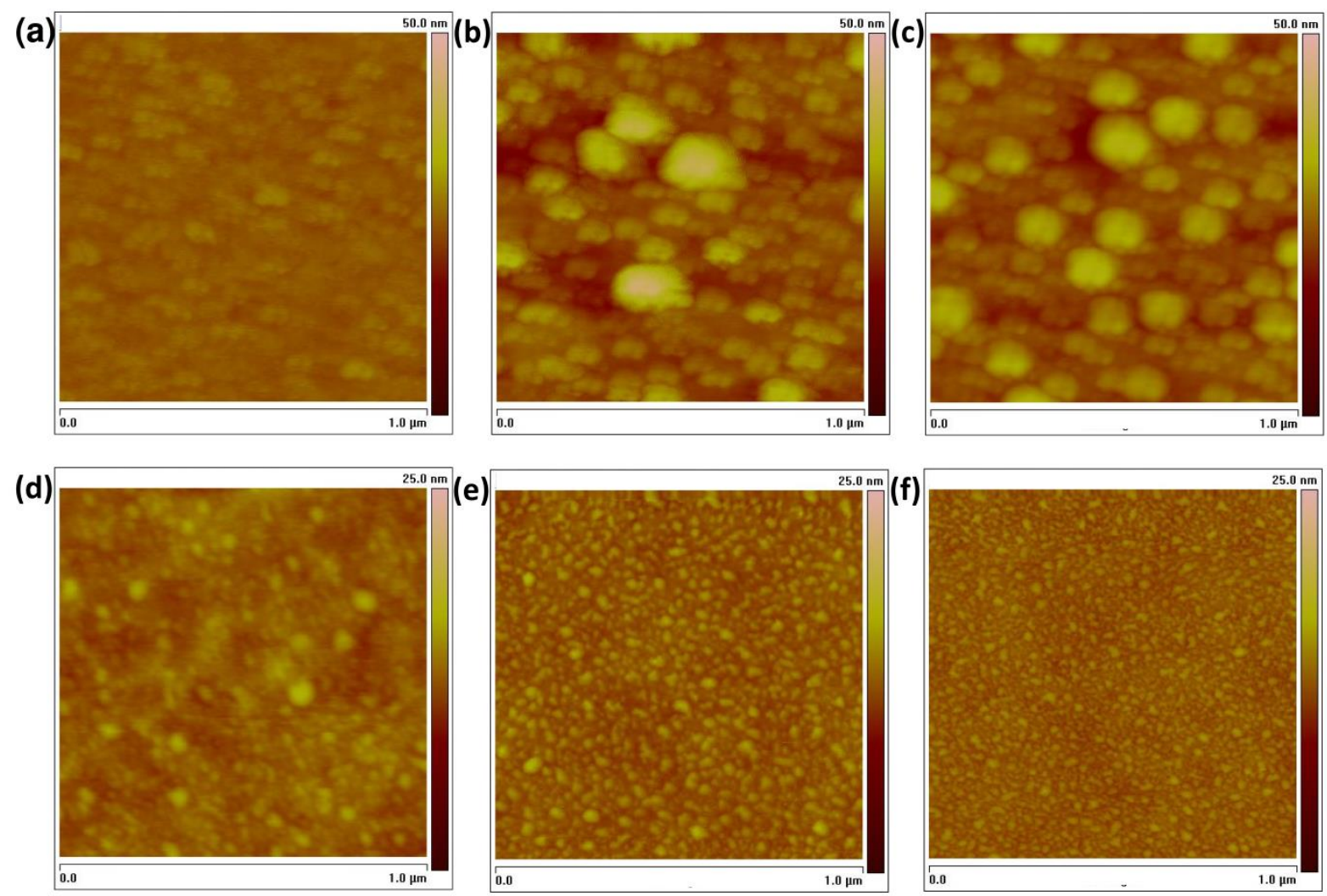

Figure S1: AFM images for (a) pristine PMMA (b) PMMAox 5.2 (c) PMMAox 7.9 (d) PS (e) Psox 5.2 and (c) PSox ${ }_{7.9 \mathrm{~d}}$. PMMAox referes to DBD treated PMMA, PSox refers to DBD treated PS. Subscripts 5.2 and 7.9 refer to the energy dose of the plasma in $\mathrm{J} / \mathrm{cm}^{2}$. 


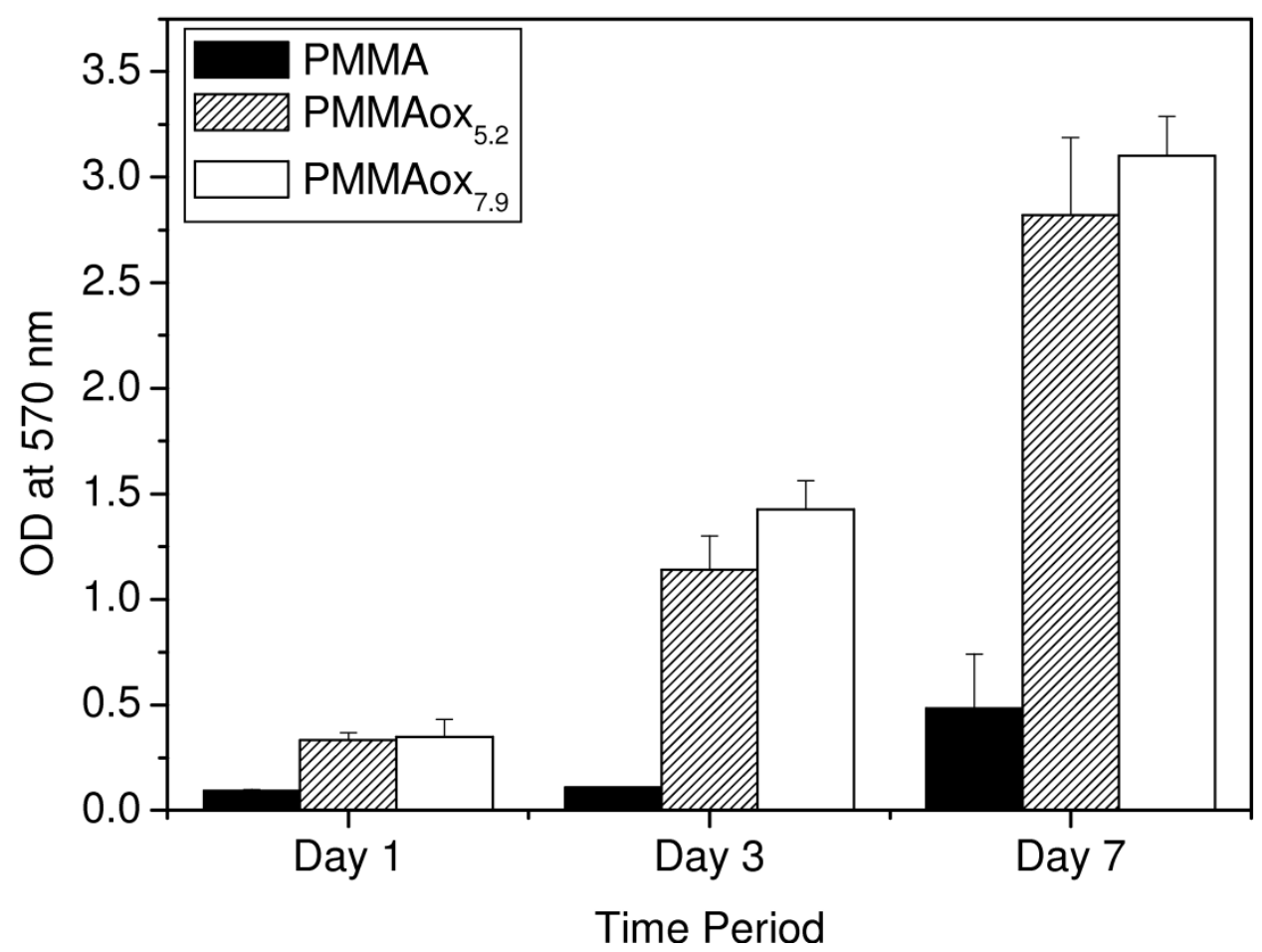

Figure S2: Cell counts for hFOBs on PMMA surfaces at 1, 3 and 7 in culture. PMMAox referes to DBD treated PMMA, PSox refers to DBD treated PS. Subscripts 5.2 and 7.9 refer to the energy dose of the plasma in $\mathrm{J} / \mathrm{cm}^{2}$. Experiment were done with $\mathrm{n}=3$ and repeated twice.

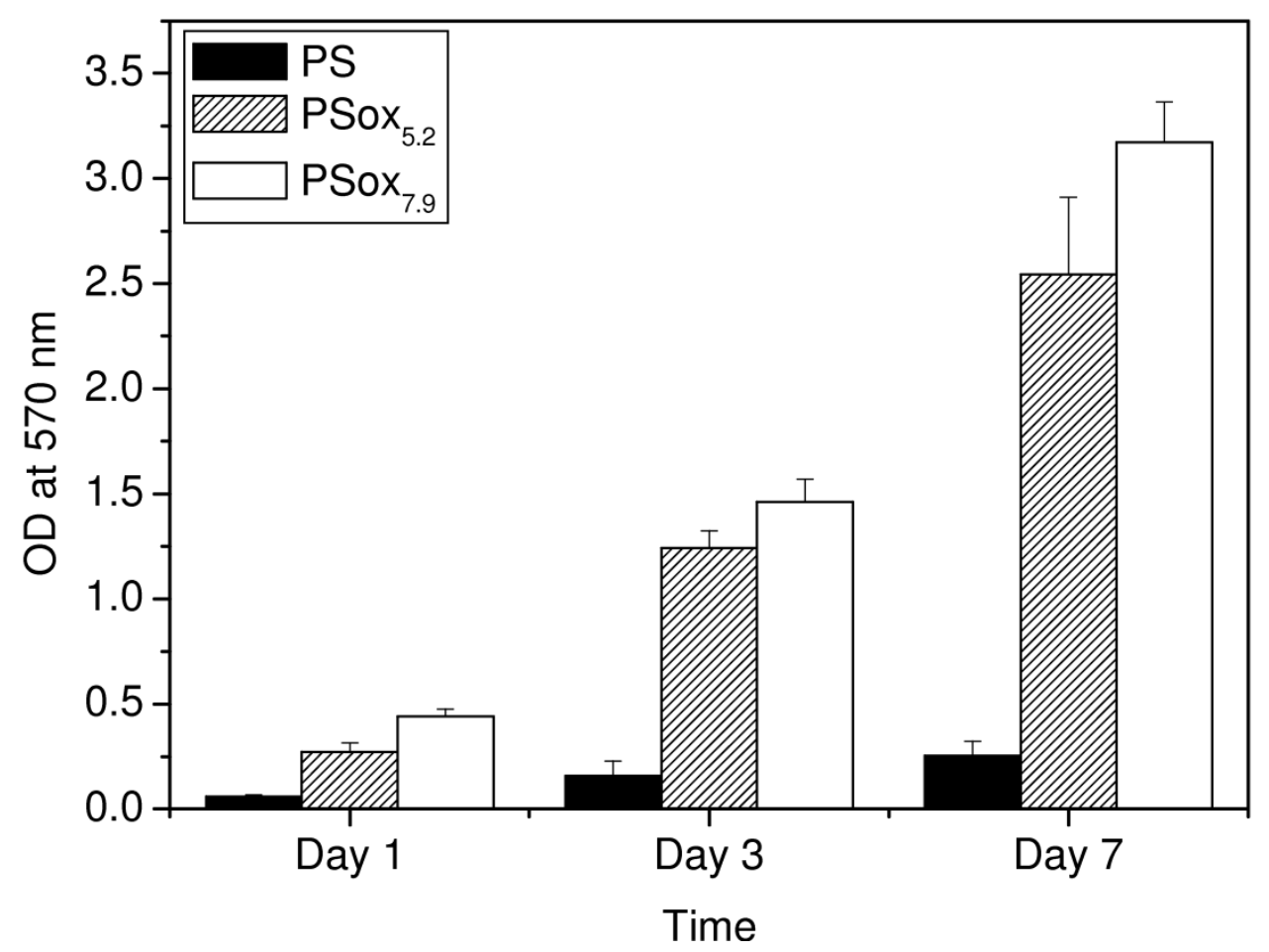

Figure S3: MTT assay for hFOBs on PS surfaces at 1, 3 and 7 in culture. PMMAox referes to DBD treated PMMA, PSox refers to DBD treated PS. Subscripts 5.2 and 7.9 refer to the energy dose of the plasma in $\mathrm{J} / \mathrm{cm}^{2}$. Experiment were done with $\mathrm{n}=3$ and repeated twice. 